\title{
Assessment of knowledge on cardiovascular disease risk factors by postal survey in residents of Małopolska Voivodeship. Małopolska CArdiovascular PReventive Intervention Study (M-CAPRI)
}

\author{
Anna Waśniowska', Grzegorz Kopeć2 , Krystyna Szafraniec ${ }^{3}$, Witosława Misiowiec ${ }^{3}$, \\ Marcin Waligóra ${ }^{2}$, Mateusz Brózda², Agnieszka Sarnecka² ${ }^{2}$ Jakub Podolec $^{4}$, Anita Orzeł-Nowak ${ }^{5}$, \\ Andrzej Pająk ${ }^{3}$, Piotr Podolec ${ }^{2}$ \\ ${ }^{1}$ Department of Diagnostics, John Paul II Hospital, Kraków, Poland \\ 2 Department of Cardiac and Vascular Diseases, Institute of Cardiology, Jagiellonian University Medical College, \\ John Paul II Hospital, Kraków, Poland \\ ${ }^{3}$ Department of Epidemiology and Population Studies, Institute of Public Health, Faculty of Health Sciences, Jagiellonian \\ University Medical College, Kraków, Poland \\ ${ }^{4}$ Department of Interventional Cardiology, Institute of Cardiology, Jagiellonian University Medical College, John Paul II \\ Hospital, Kraków, Poland \\ ${ }^{5}$ Instytute of Nursing and Midwifery, Faculty of Health Sciences, Jagiellonian University Medical College, Kraków, Poland \\ Waśniowska A, Kopeć G, Szafraniec K, Misiowiec W, Waligóra M, Brózda M, Sarnecka A, Podolec J, Orzeł-Nowak A, Pająk A, Podolec P. \\ Assessment of knowledge on cardiovascular disease risk factors by postal survey in residents of Małopolska Voivodeship. Małopolska \\ CArdiovascular PReventive Intervention Study (M-CAPRI). Ann Agric Environ Med. 2017; 24(2): 201-206. doi: 10.5604/12321966.1228400
}

\begin{abstract}
Introduction. Education is a key tool in the prevention of cardiovascular disease (CVD). Education programmes require monitoring of their effectiveness.

Objectives. 1) to introduce postal screening for the assessment of knowledge on CVD risk factors (RFs) for the Polish population, 2) to assess this knowledge in adult residents of Małopolska Voivodeship, and 3) to assess whether knowledge on RFs is related to age, gender, place of residence, level of education and family history of CVD.

Materials and method. Anonymous questionnaires were posted to a random sample of 5,000 residents of Małopolska Voivodeship in Poland. Results were presented as proportions of participants who listed RFs correctly. A series of multiple logistic regression models was used to assess the associations of knowledge on RFs with the potential determinants.

Results. 1,126 completed questionnaires were returned. Over $35 \%$ of respondents could not list a single RF and $14 \%$ listed only 1-2 RFs. About $40 \%$ named 3-5 and only $12 \%$ listed 6 or more RFs. About a half of the respondents listed incorrectly from 1-8 characteristics as being associated with higher risk of CVD. In the multivariate analysis, knowledge on RFs was not significantly associated with age. Level of education was the strongest determinant of knowledge. Male rural and small town residents had less knowledge, whereas women with a family history of CVD had more knowledge on some CVD RFs. Conclusions. Using a postal questionnaire for the assessment of knowledge of CVD RFs in the population of Małopolska Voivodeship appeared to have serious limitations due to low participation in the study. Despite this, the results of the study indicate that knowledge on CVD RFs is insufficient. Female gender and higher education were related to more prevalent knowledge on RFs. Family history of CVD was related to better knowledge in women only. Male residents of rural areas and small towns had slightly less knowledge on CVD RFs.
\end{abstract}

Key words

cardiovascular disease, health knowledge, risk factors, postal survey

\section{INTRODUCTION}

During the last 20 years in Poland, mortality from diseases of the circulatory system have decreased by about $40 \%$, and in 2010 the rate was 466/100,000 in women and 437/100,000 in men. However, this group of diseases, which includes all clinical manifestations of cardiovascular disease (CVD), is still the most common cause of death, and there is some

Address for correspondence: Anna Waśniowska, Department of Diagnostics, John Paul II Hospital, Kraków, Poland

E-mail:anwasniowska@gmail.com

Received: 16 January 2014; accepted: 11 July 2014; first published on March, 2017 evidence that it is a second cause of Potential Years of Life Lost (PYLL) in Poland $[1,2,3]$.

Among the diseases of the circulatory system the most common cause of deaths was ischemic heart disease (IHD) $-45,832$ deaths, and the second was cerebrovascular disease - 35,570 deaths, which accounted for $26.4 \%$ and $20.4 \%$ of all deaths due to the diseases of circulatory system, and $12.2 \%$ and $9.5 \%$ of deaths from all causes, respectively [1].

The largest impact on changes in mortality from CVD are the changes in exposure to risk factors (RFs) $[4,5,6]$. Changes in RFs, mainly through smoking and hypercholesterolaemia, accounted for $54 \%$ of the decrease in IHD mortality in Poland 
which occurred in 1991-2005 [7]. The Fifth Joint Task Force of the European Society of Cardiology and Other Societies on Cardiovascular Disease Prevention in Clinical Practice postulate that prevention methods which aim to reduce exposure to RFs, have the greatest potentials for controlling CVDs [4]. CVD prevention is based on two strategies: population strategy and high-risk strategy. Population strategy aims to the influence general population, i.e. both patients and healthy persons, regardless of whether they are at high or low risk. The high-risk strategy includes activities that identify people at high risk of CVD and provide them with appropriate care. Population strategy includes activities such as health promotion, health education, legislation, production, distribution and promotion of healthy food, facilitating access to sports and recreation activities, and improving access to medical diagnostics and treatment $[4,8,9]$.

Education is particularly important component of high risk strategy and should be one of the main activities in every CVD prevention programme. At the population level, education requires monitoring of its effectiveness. To introduce monitoring, a method is needed which allows assessment of the knowledge on CVD risk and the possibility of its reduction. For the population studied, knowledge can be estimated by using various forms of screening survey ('door to door', out-patient clinic visits, telephone surveys, email surveys, etc.). Postal survey was used widely for this purpose $[10,11,12,13,14,15,16,17]$. One of the disadvantages of this type of survey is low control over participation. However, many studies reached a participation rate of over $60 \%$, and some studies even over $80 \%$ [13, 14, 15, 16, 17]. Despite the unquestionable advantage of postal survey, which is particularly important in countries with a low budget for research, it's simplicity and low costs, no attempts have been made in Poland to assess the state of knowledge on CVD prevention using this method.

\section{OBJECTIVES}

The aims of the study were:

1) to introduce postal screening for the assessment of knowledge on CVD RFs for Polish population;

2) to assess this knowledge in adult residents of Małopolska Voivodeship;

3) to assess whether knowledge on RFs is related to age, gender, place of residence, level of education and family history of CVD.

\section{MATERIALS AND METHOD}

The presented study was carried out as part of a baseline observation in the project 'Małopolska CArdiovascular PReventive Intervention Study (M-CAPRI)'.

The study sample comprised 5,000 men and women aged 18 years or older, selected by simple random sampling from the registry of Małopolska Voivodeship residents. The sample selected had very similar distribution by gender and age with the population of the Małopolska Voivodeship. A standard questionnaire was sent by post to the participants of the study, and included a letter from the Voivodeship Specialist for Cardiology which explained the rationale of the study. Participants were asked to anonymously complete the questionnaire and return it in the enclosed addressed envelope. Participants did not bear the costs of posting. Knowledge of CVD RFs was assessed by using a set of two questions which was a modification of the questionnaire used in the study on the effectiveness of the National Programme of Primary Prevention [18]. The first question allowed assessment of whether a respondent was familiar with the term 'risk factor' (RF); the second was an open question in which the participant was asked to list all known RFs. The answers were coded using a standard coding system. Results were presented as percentages of correct answers by gender, age group, education (primary, secondary, university degree), place of residence (Krakow, town, village), and by family history of CVD. Percentages were age-standardized using weights calculated for the sample selected. Significance of the differences in proportions was assessed by chi $^{2}$ test. A series of multiple logistic regression models was used to assess the associations of knowledge on each RF separately with the potential determinants. In these models, each participant's age was entered as a continuous variable. Education, place of residence and family history of CVD were all entered as categorical variables. Statistical significance was accepted at the level $\mathrm{p}<0.05$. All analyses were conducted with Statistica PL ver. 10.

\section{RESULTS}

Participation in the study is presented in Table 1 . Of the 5,000 people to whom the questionnaire was sent, 1,150 replied. 24 questionnaires were returned blank or with missing data on gender or age. Finally, the analysis included 1,126 persons (22.5\% of the initial sample) aged $18-79$. Participation was higher among women compared to men, $26 \%$ and $19 \%$, respectively $(\mathrm{p}<0.001)$. Both in men and in women, participation was higher in the older age groups ( $\mathrm{p}$ for trend $<0.001$ ).

Table 1. Participation in the study by sex and age group

\begin{tabular}{lccccccccc}
\hline Age & \multicolumn{3}{c}{ Women } & \multicolumn{3}{c}{ Men } & \multicolumn{3}{c}{ Total } \\
\hline groups & $\mathrm{N}$ & $\mathrm{n}$ & $\%$ & $\mathrm{~N}$ & $\mathrm{n}$ & $\%$ & $\mathrm{~N}$ & $\mathrm{n}$ & $\%$ \\
\hline $18-19$ & 95 & 17 & 17.9 & 111 & 13 & 11.7 & 206 & 30 & 14.6 \\
\hline $20-24$ & 267 & 60 & 22.5 & 271 & 42 & 15.5 & 538 & 102 & 19.0 \\
\hline $25-29$ & 268 & 49 & 18.3 & 280 & 28 & 10.0 & 548 & 77 & 14.1 \\
\hline $30-34$ & 269 & 47 & 17.5 & 269 & 36 & 13.4 & 538 & 83 & 15.4 \\
\hline $35-39$ & 249 & 59 & 23.7 & 237 & 36 & 15.2 & 486 & 95 & 19.5 \\
\hline $40-44$ & 216 & 56 & 25.9 & 236 & 36 & 15.3 & 452 & 92 & 20.4 \\
\hline $45-49$ & 185 & 49 & 26.5 & 193 & 32 & 16.6 & 378 & 81 & 21.4 \\
\hline $50-54$ & 209 & 47 & 22.5 & 224 & 40 & 17.9 & 433 & 87 & 20.1 \\
\hline $55-59$ & 258 & 71 & 27.5 & 219 & 53 & 24.2 & 477 & 124 & 26.0 \\
\hline $60-64$ & 216 & 85 & 39.4 & 203 & 50 & 24.6 & 419 & 135 & 32.2 \\
\hline $65-69$ & 154 & 69 & 44.8 & 123 & 53 & 43.1 & 277 & 122 & 44.0 \\
\hline $70-74$ & 131 & 44 & 33.6 & 85 & 36 & 42.4 & 216 & 80 & 37.0 \\
\hline$>=75$ & 23 & 10 & 43.5 & 9 & 8 & 88.9 & 32 & 18 & 56.3 \\
\hline Total & $\mathbf{2 5 4 0}$ & $\mathbf{6 6 3}$ & $\mathbf{2 6 . 1}$ & $\mathbf{2 4 6 0}$ & $\mathbf{4 6 3}$ & $\mathbf{1 8 . 8}$ & $\mathbf{5 0 0 0}$ & $\mathbf{1 1 2 6}$ & $\mathbf{2 2 . 5}$ \\
\hline p for & & & $<0.001$ & & & $<0.001$ & & & $<0.001$ \\
trend & & & & & & & & &
\end{tabular}

$\mathrm{N}-\mathrm{No}$. of residents of Małopolska Voivodeship to whom questionnaires were sent $\mathrm{n}$ - No. of residents of Małopolska Voivodeship who returned questionnaires which were accepted for analysis 
About $36 \%$ of respondents could not list a single CVD RF, $14 \%$ listed only $1-2$ RFs correctly and $39 \%$ named $3-5$ factors. Only $12 \%$ listed 6 or more RFs, including 3 persons who listed the maximum of 9 RFs. In addition, $46 \%$ of respondents listed incorrectly 1-8 characteristics as being associated with higher risk of CVD. Smoking was the most commonly recognized RF (46\% of respondents), followed by chronic stress (37\%), low physical activity (36\%), poor diet (34\%) and obesity (33\%). Hypertension was mentioned less frequently, (27\%) and only $13 \%$ of respondents mentioned high level of total blood cholesterol. Knowledge on LDL-cholesterol was much lower - only $3 \%$ of respondents indicated it as CVD $\mathrm{RF}$, and only a few persons mentioned low concentration of HDL-cholesterol. Diabetes and alcohol consumption were recognized even less frequently than high cholesterol (11\% each). One person mentioned that lack of vaccination against influenza may increase CVD risk.
The percentage of respondents who had knowledge of the CVD RFs is shown in Tables 2 and 3 by age, gender, education, place of residence and family history of cardiovascular disease. Compared to men, women were more likely to indicate hypertension ( $31.5 \%$ and $21.2 \%$, respectively; $<<0.001)$, high cholesterol (15.7\% and $8.6 \%$, respectively; $\mathrm{p}<0.001)$, obesity and overweight $(36.2 \%$ and $29 \%$, respectively; $\mathrm{p}<0.05)$ and low physical activity (39.4\% and $32.4 \%$, respectively; $\mathrm{p}<0.05)$. In men, knowledge of CVD RFs was not associated with age. In women, there were significant differences in knowledge on obesity, unhealthy diet, low physical activity and chronic stress by age group, although no clear trend with age was found.

There were significant differences in knowledge on RFs by education, with the highest proportion of participants who had knowledge in the group with university education. Urban males (residents of Krakow and small towns) had better

Table 2. Percent of persons having knowledge on CVD risk factors by gender and age group

\begin{tabular}{|c|c|c|c|c|c|c|c|c|c|c|c|c|}
\hline \multirow{3}{*}{ CVD risk factors } & \multicolumn{6}{|c|}{ Women } & \multicolumn{6}{|c|}{ Men } \\
\hline & \multicolumn{3}{|c|}{ Age group } & \multirow[b]{2}{*}{$P$} & \multicolumn{2}{|r|}{ Total } & \multicolumn{3}{|c|}{ Age group } & \multirow[b]{2}{*}{$P$} & \multicolumn{2}{|r|}{ Total } \\
\hline & $18-34$ & $35-54$ & $55-79$ & & $\%$ & Age standardized \% & $18-34$ & $35-54$ & $55-79$ & & $\%$ & Age standardized \% \\
\hline Hypertension & 28.3 & 36.0 & 30.1 & NS & 31.5 & 31.5 & 17.6 & 22.9 & 22.0 & NS & 21.2 & 20.7 \\
\hline High level of TC & 14.5 & 17.1 & 15.4 & NS & 15.7 & 15.6 & 4.2 & 8.3 & 11.5 & NS & 8.6 & 7.6 \\
\hline Diabetes & 12.7 & 14.2 & 9.7 & NS & 11.9 & 12.3 & 5.0 & 8.3 & 10.5 & NS & 8.4 & 7.7 \\
\hline Unhealthy diet & 37.6 & 42.2 & 28.3 & $<0.01$ & 35.1 & 36.3 & 30.3 & 36.1 & 29.5 & NS & 31.7 & 32.2 \\
\hline Alcohol & 15.0 & 9.5 & 11.8 & NS & 11.9 & 12.2 & 8.4 & 10.4 & 10.0 & NS & 9.7 & 9.5 \\
\hline Smoking & 47.4 & 48.3 & 40.9 & NS & 44.9 & 45.7 & 38.7 & 50.7 & 42.5 & NS & 44.1 & 44.0 \\
\hline Low physical activity & 43.4 & 46.4 & 31.5 & $<0.01$ & 39.4 & 40.8 & 26.9 & 36.1 & 33.0 & NS & 32.4 & 31.8 \\
\hline Chronic stress & 36.4 & 51.2 & 30.5 & $<0.001$ & 38.6 & 39.6 & 34.5 & 33.3 & 34.5 & NS & 34.1 & 34.1 \\
\hline
\end{tabular}

Table 3. Percent of persons having knowledge on CVD risk factors by level of education, place of residence and family history of CVD

\begin{tabular}{|c|c|c|c|c|c|c|c|c|c|c|c|}
\hline \multirow{2}{*}{ CVD risk factors } & \multicolumn{4}{|c|}{ Education } & \multicolumn{4}{|c|}{ Place of residence } & \multicolumn{3}{|c|}{ Family history of CVD } \\
\hline & primary & secondary & university & $P$ & rural & small town & Kraków & $\mathrm{P}$ & yes & no & $P$ \\
\hline & \multicolumn{11}{|c|}{ Men } \\
\hline Hypertension & 16.8 & 17.2 & 31.9 & $<0.01$ & 17.0 & 22.3 & 25.9 & NS & 24.3 & 18.9 & NS \\
\hline High level of TC & 6.4 & 4.5 & 16.3 & $<0.001$ & 4.4 & 9.6 & 13.4 & $<0.05$ & 10.3 & 7.4 & NS \\
\hline Diabetes & 6.4 & 3.2 & 17.8 & $<0.001$ & 4.4 & 6.4 & 17.3 & $<0.001$ & 11.2 & 6.2 & NS \\
\hline Unhealthy diet & 26.6 & 31.2 & 39.3 & NS & 30.7 & 37.6 & 38.9 & $<0.05$ & 31.3 & 33.2 & NS \\
\hline Alcohol & 8.7 & 9.6 & 11.1 & NS & 11.9 & 12.8 & 11.1 & NS & 9.8 & 9.8 & NS \\
\hline Smoking & 38.2 & 42.7 & 51.9 & NS & 38.3 & 49.5 & 48.9 & $<0.05$ & 47.7 & 41.4 & NS \\
\hline Low physical activity & 20.8 & 32.5 & 46.7 & $<0.001$ & 23.0 & 38.9 & 37.8 & $<0.01$ & 35.0 & 31.2 & NS \\
\hline Chronic stress & 27.8 & 30.6 & 47.4 & $<0.001$ & 30.8 & 32.5 & 41.7 & NS & 36.5 & 33.2 & NS \\
\hline Hypertension & 14.4 & 32.6 & 40.6 & $<0.001$ & 29.1 & 30.7 & 36.1 & NS & 34.9 & 27.6 & $<0.05$ \\
\hline High level of TC & 7.5 & 14.9 & 21.3 & $<0.01$ & 14.9 & 15.1 & 17.2 & NS & 16.5 & 14.8 & NS \\
\hline Diabetes & 6.2 & 11.5 & 15.8 & $<0.05$ & 10.3 & 11.9 & 13.9 & NS & 13.2 & 10.3 & NS \\
\hline Obesity or overweight & 17.8 & 32.6 & 50.4 & $<0.001$ & 30.3 & 36.2 & 44.4 & $<0.01$ & 38.1 & 34.1 & NS \\
\hline Unhealthy diet & 19.2 & 31.8 & 47.6 & $<0.001$ & 30.7 & 37.6 & 38.9 & NS & 37.3 & 32.8 & NS \\
\hline Alcohol & 6.2 & 10.7 & 16.5 & $<0.01$ & 11.9 & 12.8 & 11.1 & NS & 12.4 & 11.4 & NS \\
\hline Smoking & 24.7 & 42.5 & 58.7 & $<0.001$ & 38.3 & 49.5 & 48.9 & $<0.05$ & 48.9 & 40.3 & $<0.05$ \\
\hline Low physical activity & 19.2 & 33.7 & 56.7 & $<0.001$ & 36.0 & 42.2 & 41.1 & NS & 42.2 & 36.2 & NS \\
\hline Chronic stress & 21.2 & 33.3 & 54.3 & $<0.001$ & 33.3 & 44.0 & 40.6 & $<0.05$ & 41.0 & 35.9 & NS \\
\hline
\end{tabular}


knowledge on RFs than rural males. With the exception to overweight, smoking and chronic stress, differences in knowledge on RFs by place of residence were not significant in women. Family history of CVD was associated with knowledge on hypertension and smoking in women only (Tab. 3).

In the multivariate analysis, which included age, education, place of residence and family history of CVD, knowledge on RFs was not significantly associated with age, in both men and in women. In both genders, the most significant determinant of knowledge on RFs was the level of education. On average, women with university education were 3-5 times more likely to have knowledge on RFs, compared to women with primary education, and women with secondary education were 2-3 times more likely to have knowledge on RFs than women with primary education. However, the relationship was not significant for knowledge on diabetes and alcohol consumption. In men, a higher level of education was also associated with increased odds of knowledge on RFs. Nevertheless, compared to women, the relationship was weaker. Compared to men with primary education, men with secondary education had better knowledge on low physical activity only. Men with university education were more than twice as likely to have knowledge on high blood pressure, overweight and obesity, low physical activity and chronic stress, than men with primary education. Similar average estimates of the odds ratio were confirmed for high cholesterol and diabetes, but these relations were not statistically significant. In men, there was no significant relationship between having a university education and indication on unhealthy diet, high consumption of alcohol and smoking as RFs for CVD. In both genders, place of residence had little effect on knowledge on RFs. Significant results on diabetes and unhealthy diet were found only in men. Compared to male residents of Krakow, men living in small towns and villages knew less frequently that diabetes is an RF. Men living in villages were less likely than male residents of Krakow to know that an unhealthy diet is a CVD RF. In women, there was no significant association between place of residence and knowledge on RFs. Women with a family history of CVD were more likely to know that high blood pressure, unhealthy diet, smoking, low physical activity and chronic stress, increase the risk of CVD. Relation between family history of CVD and knowledge on other RFs was not significant. There was no significant association between family history of CVD and knowledge on CVD RFs in men. (Tab. 4).

\section{DISCUSSION}

Using a postal questionnaire sent only once to study participants, without any reminder, appeared to have serious limitations for the assessment of knowledge of CVD RFs in the population of Małopolska Voivodeship. Despite the random selection of the study sample, the low participation rate does not allow acceptance of the results as being representative for the general population. This

Table 4. Adjusted for covariates odds ratio for having knowledge on CVD risk factors by education, place of residence and family history of CVD

\begin{tabular}{|c|c|c|c|c|c|}
\hline \multirow{4}{*}{ CVD risk factors } & \multicolumn{2}{|c|}{ Education } & \multicolumn{2}{|c|}{ Place of residence } & Family history of CVD \\
\hline & \multicolumn{2}{|c|}{ OR $(95 \% \mathrm{Cl})$} & \multicolumn{2}{|c|}{ OR $(95 \% \mathrm{Cl})$} & OR $(95 \% \mathrm{Cl})$ \\
\hline & \multicolumn{5}{|c|}{ Men } \\
\hline & Secondary ${ }^{1}$ & University $^{1}$ & Rural $^{2}$ & Small town ${ }^{2}$ & Family history of CVD ${ }^{3}$ \\
\hline Hypertension & $1.04(0.57-1.89)$ & $2.26(1.22-4.16)$ & $0.90(0.48-1.70)$ & $1.03(0.57-1.86)$ & $1.37(0.86-2.19)$ \\
\hline High level of TC & $0.61(0.22-1.67)$ & $2.35(0.99-5.56)$ & $0.50(0.19-1.35)$ & $0.94(0.42-2.09)$ & $1.23(0.62-2.44)$ \\
\hline Diabetes & $0.43(0.14-1.35)$ & $2.21(0.88-5.48)$ & $0.36(0.14-0.98)$ & $0.39(0.16-0.94)$ & $1.94(0.94-3.99)$ \\
\hline Obesity or overweight & $1.19(0.70-2.04)$ & $2.42(1.38-4.24)$ & $0.84(0.47-1.48)$ & $0.84(0.49-1.44)$ & $1.25(0.82-1.90)$ \\
\hline Unhealthy diet & $1.03(0.62-1.70)$ & $1.28(0.74-2.20)$ & $0.53(0.30-0.92)$ & $0.80(0.47-1.34)$ & $0.90(0.60-1.37)$ \\
\hline Alcohol & $1.02(0.47-2.22)$ & $1.15(0.50-2.67)$ & $0.73(0.30-1.76)$ & $1.03(0.47-2.29)$ & $0.93(0.50-1.75)$ \\
\hline Smoking & $1.10(0.69-1.74)$ & $1.50(0.90-2.51)$ & $0.68(0.40-1.15)$ & $0.97(0.59-1.61)$ & $1.21(0.82-1.78)$ \\
\hline Low physical activity & $1.78(1.06-2.99)$ & $3.22(1.84-5.64)$ & $0.88(0.50-1.56)$ & $1.56(0.92-2.65)$ & $1.11(0.74-1.69)$ \\
\hline \multirow{2}{*}{ Chronic stress } & \multicolumn{5}{|c|}{ Women } \\
\hline & Secondary ${ }^{1}$ & University $^{1}$ & Rural $^{2}$ & Small town ${ }^{2}$ & Family history of CVD ${ }^{3}$ \\
\hline Hypertension & $3.26(1.87-5.69)$ & $4.89(2.74-8.74)$ & $0.97(0.63-1.50)$ & $0.87(0.56-1.34)$ & $1.47(1.02-2.11)$ \\
\hline High level of TC & $2.43(1.15-5.12)$ & $3.86(1.80-8.24)$ & $1.08(0.62-1.87)$ & $0.95(0.55-1.65)$ & $1.20(0.76-1.90)$ \\
\hline Diabetes & $2.03(0.89-4.66)$ & $2.85(1.23-6.61)$ & $0.82(0.44-1.52)$ & $0.89(0.49-1.62)$ & $1.51(0.90-2.53)$ \\
\hline Obesity or overweight & $2.18(1.29-3.66)$ & $4.36(2.55-7.46)$ & $0.69(0.45-1.06)$ & $0.79(0.52-1.21)$ & $1.39(0.97-1.98)$ \\
\hline Unhealthy diet & $1.73(1.04-2.87)$ & $3.28(1.95-5.53)$ & $0.84(0.54-1.29)$ & $1.04(0.68-1.60)$ & $1.54(1.08-2.20)$ \\
\hline Alcohol & $1.85(0.83-4.15)$ & $3.27(1.45-7.37)$ & $1.38(0.73-2.59)$ & $1.32(0.71-2.47)$ & $1.20(0.72-2.00)$ \\
\hline Smoking & $2.10(1.31-3.35)$ & $4.03(2.45-6.61)$ & $0.82(0.54-1.24)$ & $1.15(0.76-1.75)$ & $1.72(1.21-2.43)$ \\
\hline Low physical activity & $1.95(1.18-3.23)$ & $5.25(3.10-8.87)$ & $1.11(0.72-1.71)$ & $1.24(0.80-1.90)$ & $1.72(1.20-2.46)$ \\
\hline Chronic stress & $1.72(1.05-2.82)$ & $4.19(2.51-6.98)$ & $0.97(0.63-1.49)$ & $1.35(0.89-2.07)$ & $1.51(1.06-2.15)$ \\
\hline
\end{tabular}


applies especially to the younger age groups, but participation of about $40 \%$, which occurred in respondents aged over 60 , is also unsatisfactory. The inhabitants of Malopolska Voivodeship were not ready to cooperate in research which could provide knowledge to allow the making of strategy to control CVD (the leading cause of death) more effective. Although efforts were undertaken to limit the influence of disparities in participation between the age groups by using a standardization procedure, respondents differed from the population of Malopolska Voivodeship in the distribution by education group and place of residence (urban vs. rural) [1]. In some studies in which a postal survey was used in other countries, the participation rate was also low $[10,11$, $12]$, but in many other studies participation exceeded $60 \%$ or even $80 \%[13,14,15,16,17]$. However, in the latter studies, one or more reminder or other techniques were used to increase the response rate. The use of such techniques was not possible in the presented study due to the anonymous participation. However, it is unlikely that application of such methods would have increased participation to a level which would assure that the results could be regarded as representative for the general population. Despite this, in future studies, resignation from anonymous data collection could be considered, but it seems that there is a need to develop other, more reliable methods than postal survey for the assessment of knowledge on health problems in Poland.

The applied questionnaire allowed verification of the level of knowledge on CVD RFs on a high level of operability, i.e participants were asked to list RFs without giving them several possible answers to chose from. It is obvious that the percentage of people who listed RFs correctly was lower than that obtained in studies in which respondents could select correct answers from a pre-prepared list of RFs. However, it is still possible that the estimates obtained are lower than the true numbers for the general population of Małopolska Voivodeship. The results of the WOBASZ and POLKARD projects in which the method of direct interview was used and higher participation rates were achieved, indicated that the knowledge on CVD RFs is more prevalent. In the WOBASZ project, in which the knowledge on CVD RFs was not assessed at a high level of operability, over $60 \%$ of respondents correctly identified that heart attack and stroke are main complications of hypertension [19]. However, it should be noted that besides the outcomes on hypertension, knowledge on CVD prevention among respondents of the WOBASZ study were rated critically, similar to findings from some Polish and foreign studies in which the knowledge was examined among the general population $[20,21]$. In the POLKARD study, conducted in patients of 66 general practice clinics and in which questionnaire similar to our study was used, the percentages of patients who indicated RFs correctly were also higher, with the sole exception of diabetes [18]. The differences between the presented results and the results of the POLKARD study can also be explained by the fact that clinic patients have hypertension or hypercholesterolemia more frequently, and more often have a history of myocardial infarction or stroke, compared to the general population [22]. The current results are similar to those obtained in a study of adults at a young age - The CARDIA Study in the USA, where knowledge on CVD RFs was assessed at a similar level of operability [23].

Despite limitations in the interpretation of the presented results due to low participation, there is the intriguing finding that more than one-third of the respondents could not name a single RF, and depending on the RF, only $1 \%-46 \%$ of respondents could name them correctly. The information that RFs which are modifiable and require qualified medical assistance, such as hypercholesterolaemia, hypertension and diabetes, were rarely listed seems worrying. On the other hand, stress was mentioned quite often as CVD RF, a finding that should be interpreted critically. It is unlikely that more than one-third of respondents could have accurate knowledge about the risks of chronic psychosocial stress corresponding with the present state of knowledge [24]. Assigning importance to the role of 'stress' can be considered rather as a factor which deflects attention from the essential problems of prevention, similar to the other characteristics listed incorrectly as CVD RFs by $46 \%$ of respondents. Although the percentages of people who had knowledge on RFs should be interpreted with the considerable reservations, including all concerns mentioned above, the results on determinants of knowledge on CVD RFs seem to be more reliable. Observations on the relation between the knowledge on CVD prevention and education or the family history of cardiovascular disease, was also found in other studies, including Polish studies $[19,25,26,27]$. Also, it is plausible that more educated people have better knowledge on RFs and that women with a family history of CVD are more likely to experience counseling on CVD RFs, as well as that men from Krakow tend to have more knowledge than men from small towns and villages. As a consequence, it is possible that the differences in the knowledge on CVD RFs may contribute to health inequalities by gender, place of residence and social status, which were broadly reported earlier [28].

\section{CONCLUSIONS}

Using a postal questionnaire for the assessment of knowledge of CVD RFs in population of Małopolska Voivodeship of Poland appeared to have serious limitations due to low participation in the study. Despite this, the results of the study indicate that knowledge on CVD RFs is insufficient. Female gender and higher education were related to more prevalent knowledge on RFs. Family history of CVD was related to better knowledge in women only. Male residents of villages and small towns had slightly less knowledge on CVD RFs.

\section{Acknowledgements}

The article was prepared using data collected in the 'Programme of Prevention and Detection of Diseases of the Circulatory System in the Population of Małopolska Voivodeship', supported from the budget of the Małopolska Voivodeship.

\section{REFERENCES}

1. Rocznik demograficzny 2012. Główny Urząd Statystyczny. Warszawa 2012 (in Polish).

2. Góźdź S, Krzyżak M, Maślach D, Wróbel M, Bielska-Lasota M. Trends of Premature Mortality in Świętokrzyskie Province (Poland), years 2002-2010. Rocz Panstw Zakl Hig. 2013; 64(3): 205-210 (in Polish).

3. Krzyżak M, Maślach D,Skrodzka M, Florczyk K, Szpak A, Pędziński B et al. Joinpoint Regression Analysis of Potential Years of Life Lost due to Main Causes of Death in Poland, Years 2002-2011. SLGR. 2013; 35(48): 157-167. 
4. Perk J, De Backer G, Gohlke H, Graham I, Reiner Z, Verschuren WMM, et al. The Fifth Joint Task Force of the European Society of Cardiology and Other Societies on Cardiovascular Disease Prevention in Clinical Practice. Eur Heart J. 2012; 33(13): 1635-1701.

5. Tunstall-Pedoe H, Kuulasmaa K, Mahonen M, Tolonen H, Ruokokoski $\mathrm{E}$, Amouyel $\mathrm{P}$ for the WHO MONICA (monitoring trends and determinants in cardiovascular disease) Project. Contribution of trends in survival and coronary-event rates to changes in coronary heart disease mortality: 10-year results from 37 WHO MONICA Project populations. Lancet. 1999; 353 (9164): 1547-57.

6. Yusuf S, Hawken S, Ounpuu S, Dans T, Avezum A, Lanas F, et al. Effect of potentially modifiable risk factors associated with myocardial infarction in 52 countries (the INTERHEAR study): case-control study. Lancet. 2004; 364 (9438): 937-952.

7. Bandosz P, O’Flaherty M, Drygas W, Rutkowski M, Koziarek J, Wyrzykowski B, et al. Decline in mortality from coronary heart disease in Poland after socioeconomic transformation: modelling study. BMJ http://www.bmj.com/content/344/bmj.d8136 (access: 2014.01.11).

8. Rose G. The Strategies of Preventive Medicine. Oxford University Press, 1992.

9. Pająk A, Kozela M, Jankowski P. Zapobieganie chorobom układu krążenia w świetle nowych wytycznych europejskich towarzystw naukowych. Gdzie zlokalizować programy prewencji? Kardiol Dypl. 2012; 11(10): 9-16 (in Polish).

10. Carrington MJ, Retegan C, Johnston CI, Jennings GL, Stewart S. Cholesterol complacency in Australia: time to revisit the basics of cardiovascular disease prevention. J Clin Nurs. 2009; 18(5): 678-686.

11. Chapple A, Sibbald B, Rogers A, Roland M. Citizens' expectations and likely use of a NHS Walk-in Centre: results of a survey and qualitative methods of research. Health Expect. 2001; 4(1): 38-47.

12. Chew KK, Bremner A, Stuckey B, Earle C, Jamrozik K. Is the relationship between cigarette smoking and male erectile dysfunction independent of cardiovascular disease? Findings from a Population-Based CrossSectional Study. J Sex Med. 2009; 6(1): 222-231.

13. Stanton WR, Moffatt J, Clavarino A. Community Perceptions of Adequate Levels and Reasons for Skin Protection. Behav Med. 2005; 31(1): 5-15.

14. Brogger J, Bakke P, Eide GE, Gulsvik A. Comparison of Telephone and Postal Survey Modes on Respiratory Symptoms and Risk Factors. Am J Epidemiol. 2002; 155(6): 572-576.

15. Sutherland HJ, Beaton M, Mazer R, Kriukov V, Boyd NF. A randomized trial of the total design method for the postal follow-up of women in a cancer prevention trial. Eur J Cancer Prev. 1996; 5(3): 165-168.

16. Jinks C, Ong BN, Croft P. Postal surveys in primary care: the hidden burden. Health Expect. 2001; 4(4): 253-259.
17. Smyth RMD, Duley L, Jacoby A, Elbourne D. Women's experiences of Participating in the Magpie Trial: A postal Survey in the United Kingdom. Birth. 2009; 36(3): 220-229.

18. Pająk A, Szafraniec K, Janion M, Szpak A, Wizner B, Wolfshaut-Wolak $\mathrm{R}$, et al. for a POLKARD study. The impact of the Polish national Programme of Cardiovascular Disease Prevention on the quality of primary cardiovascular disease prevention in clinical practice. Kardiol Pol. 2010; 68(12): 1332-1340.

19. Piwońska A, Piotrowski W, Broda G. Knowledge about arterial hypertension in the Polish population: the WOBASZ study. Kardiol Pol. 2012; 70(2): 140-146.

20. Bielecki W, Kaczmarczyk-Chałas K, Piwońska A, Kozakiewicz K, Głuszek J, Biela U, et al. Świadomość zasad zapobiegania chorobom układu krążenia w populacji dorosłych mieszkańców Polski. Wyniki programu WOBASZ. Kardiol Pol. 2005; 63(6 Suppl 4): 677-681.

21. Hamner J, Wilder B. Knowledge and risk of cardiovascular disease in rural Alabama women. J Am Acad Nurse Pract. 2008; 20(6): 333-338.

22. Broda G, Cieśliński A, Rywik S, Adamus J, Rynkiewicz A. Ogólnopolski program Prewencji Choroby Wieńcowej-POLSCREEN. Zdefiniiowanie problemu, cele i metodyka badania. In: Cieśliński A, Pająk A, Podolec P, Rynkiewicz A (eds.). Ogólnopolski Program Prewencji Choroby Wieńcowej POLSCREEN. Termedia; Poznań 2006. p.(27)33-34 (in Polish).

23. Lynch EB, Liu K, Kiefe CI, Greenland P. Cardiovascular Disease Risk Factor Knowledge in Young Adults and 10-year Change in Risk Factors. The Coronary Artery Risk Development in Young Adults (CARDIA) Study. Am J Epidemiol. 2006; 164(12):1171-1179.

24. Pająk A, Podolec P, Kopeć G, Dudek D, Zdrojewski T, Drygas W, et al. Polish Forum for Prevention Guidelines on Psychosocial Cardiovascular Disease Risk Factors. Kardiol Pol. 2009; 67(9): 1048-1051.

25. Kopeć G, Sobień B, Podolec M, Dziedzic H, Zarzecka J, Loster B, et al. Knowledge of a patient-dependant phase of acute myocardial infarction in Polish adults: the role of physician's advice. Eur J Public Health. 2011; 21(5): 603-608.

26. Avis NE, McKinlay JB, Smith KW. Is Cardiovascular Risk Factor Knowledge Sufficient to Influence Behavior? Am J Prev Med. 1990; 6(3): 137-144.

27. Potvin L, Richard L, Edwards AC. Knowledge of cardiovascular disease risk factors among the Canadian population: relationships with indicators of socioeconomic status. CMAJ. 2000; 162(9 Suppl): 5-11.

28. Health inequalities in the EU - Final report of a consortium. Consortium lead: Sir Michael Marmot. European Commission Directorate-General for Health and Consumers, European Union 2013. 